\title{
SURVEY ON STREET DOG POPULATION IN POKHARA VALLEY OF NEPAL
}

\author{
M. Acharya ${ }^{1 *}$ and S. Dhakal ${ }^{2}$ \\ ${ }^{1}$ Graduate Research Assistant, Department of Animal Science, University of Arkansas, Fayetteville \\ Arkansas, USA \\ ${ }^{2}$ Graduate Research Assistant, Food Animal Health Research Program, Ohio Agricultural Research and \\ Development Center, The Ohio State University, Wooster, Ohio, USA
}

\begin{abstract}
A survey was carried out to determine the population of street dogs and people's opinion about their persistence in Pokhara Valley, Nepal. Information of street dog population was necessary to construct a future animal birth control (ABC) plans. For this, mark-resight survey method was used. Further, local residents were interviewed to know their opinion about the persistence of street dog population in that area. Among total $1767 \mathrm{dogs}, 1072$ (60.66\%) were male, 641 (36.28\%) were female and $54(3.06 \%)$ were puppies. About $367(57.25 \%)$ of the female street dogs were already spayed. A total of 371 local residents were interviewed to know their opinion about the causes of persistent street dogs in Pokhara Valley. Numerous reasons were put forward including unmanaged slaughter house (24.5\%), abandoned due to disease (15.4\%) and abandoned due to unmanageable estrus behavior (10.2\%). Future ABC programs may need to consider these factors responsible for maintaining persistent street dog population, to enable control over street dog population in an efficient and sustainable manner.
\end{abstract}

Key words: Animal birth control, street dogs, spaying, Pokhara Valley

\section{INTRODUCTION}

The bond between human and dog is believed to have begun since ten thousand years (WHO, 1990). Since then humans and dogs live together mutually benefiting with each other's existence. In developing countries people keep pet dogs for protecting their property from wild animals and human intruders (Butler and Bingham, 2000). In developed societies people believe that keeping pet dog reduces their stress, and improves their physical and mental health (Headey and Krause, 1992; APPMA.org). Keeping dogs in a house have several benefits, however they are also a major thread for human health. Besides biting, they transfer several diseases (Plant et al., 1996; Geffray, 1999). It is estimated that sixty to one hundred number of zoonotic disease could be transferred from dog to human. Rabies, echinococcosis, and Toxocara canis are the major zoonotic disease from free roaming dogs in developing countries (Reece, 2005). About 67\% of street dogs in Kathmandu Valley are infested with mites (Bindari et al., 2012). Satyal et al. (2013) reported 56\% of street dogs in Kathmandu Valley being infected with gastrointestinal nematode. It is estimated that 200 people die of rabies every year and $95 \%$ of human rabies cases are from the bite of dogs (Dr. Joshi, director at NZFHRC; personal communication). Apart part from disease, street dogs in busy streets make noise pollution, disturb pedestrians and drivers, spread garbage, fall in accidents, and pass feces everywhere.

Knowing street dog population distribution pattern helps us to conduct epidemiological studies on sources of zoonotic diseases, disease distribution pattern, and control of such diseases (Slater, 2001; Hiby et al., 2011). Very few data are available regarding street dog population in major cities of Nepal. Kakati (2012) estimated 22,288 stray dogs in the area within the ring road of Kathmandu and Lalitpur. A Survey conducted by Himalayan

Animal Rescue Team (HART, team) during 2010 reported around 1,700 dogs inside Pokhara Valley (Juliette Cunliffe, founder HART, team; personal communication). Several organizations are conducting animal birth control (ABC) programs in Kathmandu and other places of Nepal. However, understanding the numbers as well as the root causes for persistency of the street dog population are most important for controlling the street dog population in efficient and sustainable manner. So, this study was conducted in Pokhara Valley, one of the major cities of Nepal, with the objective of determining the number of street dogs as well as exploring the perception of local residents regarding the causes of persistency in the street dog population.

*Corresponding e-mail address: macharya@uark.edu 


\section{Acharya and S. Dhakal}

\section{MATERIALS AND METHODS}

\section{Study area and duration}

This study was carried out in Pokhara sub-metropolitan city. Pokhara sub-metropolitan city is located in Kaski district of central Nepal, between $83^{\circ} 58^{\prime} 30^{\prime \prime}$ to $84^{\circ} 02^{\prime} 03^{\prime \prime}$ east longitude and $28^{\circ} 10^{\prime}$ north to $28^{\circ} 16^{\prime}$ north latitude. Pokhara is surrounded by Lekhnath Municipality, Arwa and Kahun village from the west; Armala, Hemja, Chhahrepani and Lamachaur villages from the north; and Kristi Nachne Chaur, Nirmal Pokhari and Bharat Pokhari villages form the south. Pokhara has slums mainly around bus park areas. Slaughter houses are thinly scattered all over the city. The survey was conducted between December 2011 and February 2012.

\section{Survey of street dog}

We divided the total area of Pokhara into 18 parts corresponding to each ward. Each ward was then divided into two equal parts and each part was surveyed in a single day. A follow up survey was conducted on the third day as chance of missing dogs is high in a single survey (Hiby, 2005). The survey was carried out in the early morning between 6:00 am to 8:30 am. Total staffs from Himalayan animal rescue team (HART team) split into four groups and recorded dogs, excluding those inside the private property or dogs walking with owners. Markresight survey method was used for the street dog survey (Totton et al., 2010). Aspee Eden 5-1 canister spray was used to mark dogs from the distance. Previous experience showed the spray paint lasted for 5 days on the dogs. Counting was done at the time of spray. Spayed or unspayed were separated based on presence or absence of ear notch. Gender and presence or absence of ear notch was recorded at the same time. If the dog had developed teats in females or descended testes in males they were classified as adult. Dogs were classified as puppies based on their head size, leg length, and body size.

\section{Survey of local residents}

Reliable and responsible local residents, between 20 - 50 years of age, located close to the areas having maximum number of street dogs were selected for the interview. A total of 371 people irrespective of sex were interviewed to find their views regarding persistence of street dog in Pokhara Valley. A roughly equal number of people were selected from each wards. We attempted to limit our questionnaire survey roughly a minute for each person. Questionnaire surveys were conducted during dog counting.

\section{Statistical analysis}

Statistical analysis was performed with Excel 2013 (Microsoft Corporation, New York, USA). Results are presented in total numbers, percentages, and bar diagrams.

\section{RESULTS}

\section{Characteristics of street dog population}

A total of 1767 dogs were recorded inside Pokhara Valley. Among them, 1072 (60.66\%) were males, 641 $(36.27 \%)$ were females, and $54(3.07 \%)$ were puppies. The highest number of dogs (i.e. 201) were recorded in ward number 9 and lowest number of dogs (i.e. 31) were recorded in ward number 6 (Fig. 1). The number of male dogs was high in all wards compared to female dogs (Fig.2). Among 641 females, 367 (57.25\%) were spayed and $274(42.75 \%)$ were not spayed. Regarding male: female ratios of dogs, the ratio was highest (2.47) in ward 9 and lowest (1.17) in ward 3 (Fig. 3).

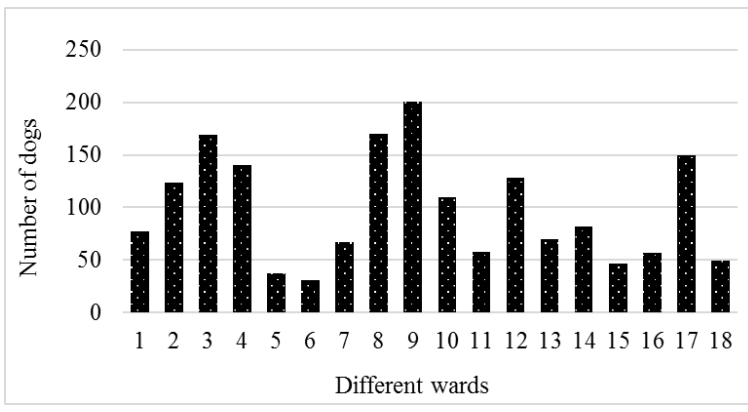

Fig. 1. Ward wise distribution of dogs in Pokhara valley 


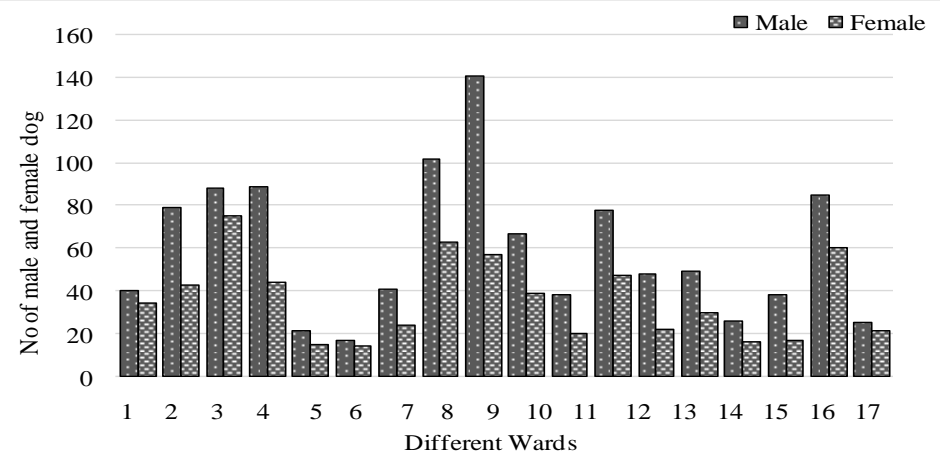

Fig. 2. Sex wise distribution of dog population in different wards inside Pokhara valley

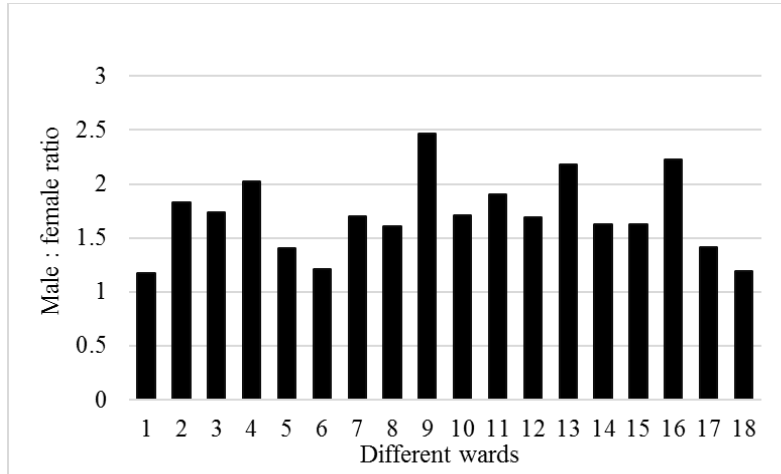

Fig. 3. Sex ratio (Male: Females) of street dogs inside Pokhara valley

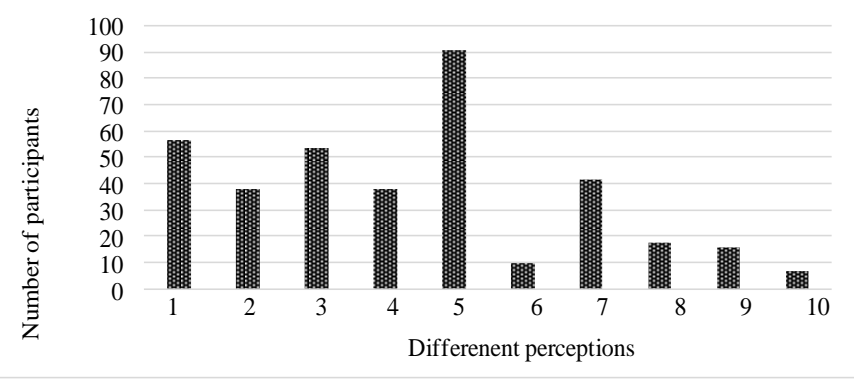

Fig. 4. People's perception about persistence of street dog inside Pokhara valley

1 = Abandoned due to sick, 2 = Sudden aggressive behavior, 3 = Estrus behavior, $4=$ Too much fond on young dogs, 5 = Too many unmanaged slaughter house, $6=$ Lack of government plan, $7=$ Too many babies, $8=$ Biting people/livestock, $9=$ Lost, and $10=$ Failure to protect crops $/$ keep thieves away. 


\section{Acharya and S. Dhakal}

\section{Public opinion regarding persistent street dog population}

In total, 371 individuals were interviewed to know their opinion about the persistent street dog population. Among them, $63.1 \%$ were male and $36.9 \%$ were female respondents. Varying responses were noted. The different responses of the public are shown in Fig. 4. The highest number of respondents (i.e. 24.53\%) pointed out that too many unmanaged slaughter house are responsible for the persistent street dog population. Respondents offered the opinion that dogs are carnivorous by nature and are easily attracted by offal. The second reason people pointed out was abandonment due to sickness. Some people approach veterinarians and treat their sick dogs while other cannot afford treatments or do not want to pay and abandon the dog. Further, owned dogs regularly visiting slaughter houses and coming into contact with several dogs are likely to contact several diseases and these dogs are never welcomed by the owners. Likewise, the third reason given is estrous behavior. During estrus, males and females travel considerable distances. In Pokhara, dogs travel from Pokhara to adjoining villages and vice-versa. Dogs that leave the city are most likely to return, but dogs from villages entering the city may not. It is because dogs in the city can easily find available garbage and offal to help them survive. Dogs which leave the house during estrus are also less likely to be accepted by the owner. Nearly $11.32 \%$ of the respondents said that the prolific breeding nature of dogs is responsible for the persistent street dog population. Dogs can produce up to 15 babies in a single litter. There will be no space to keep them all and also hard to find people who can adopt dogs, so most of them make their way to street. Breeding within the street dogs is also helping to add to the rapid increase of street dog population. Disease or other environmental factors may contribute to aggression. Roughly $10.24 \%$ of the respondents think that due to such behavior, pet dogs are thrown out of the house. Over $10 \%$ of the people said young pups are adorable, but once grown they become unmanageable. People then lose interest and expel them from house. Other reasons by respondents were: biting people or livestock, some are lost and could not figure out the way back home, and guard dog's inability to keep thieves away. Around $2.69 \%$ of respondents said that there is no proper plan from the government sector to control street and that is why the street dog number is always similar.

\section{DISCUSSION}

This study was carried out to know the street dog population in Pokhara as well as to understand the opinion of people about persistent street dog population. We noted a total of 1767 dogs including 1072 males, 641 Females and 54 pups. There is no published data regarding dog population in Pokhara Valley. Himalayan Animal Rescue Team (HART team) had carried out one survey in 2010, and according to results the total dog population in Pokhara Valley was 1705 (Juliette Cunliffe, Founder, HART team; personal communication). These numbers are similar suggesting for constant number of dogs in this city despite several animal birth control (ABC) programs.

In the past, strychnine poisoning was practiced to control the street dog population in major cities of Nepal, but this brought horrific results (Kaufman, 2004). Hormonal birth control has many side effects (Tindall, 1975). Therefore, surgical sterilization is the best method for birth control (Slone, 1988). For surgical sterilization, spaying females instead of castrating males are preferred in most countries including South Asia. In Jaipur, 60\% of female dogs were sterilized within three year period and dog population declined by one third between 1997 2002 (Jackman and Rowan, 2007). An animal birth control program lunched in Jodhpur from 2004 to 2007 surgically sterilized 61.8-86.5\% street dogs including males and females. A survey carried out in 2007 showed significant decline in the street dog population (Totton et al., 2010). In Kathmandu, the Kathmandu Animal Treatment Centre (KAT Centre) has conducted ABC program since 2004. A survey done within ring road of Kathmandu indicated a marked decrease in street dog numbers from 30,992 to 22,555 between 2006 to 2010 (Kakati, 2010). Control of zoonotic disease is another advantage of an ABC program. In Jaipur India, 10 rabies deaths were observed during 1996. However the number declined to 0 during 2002 (Jackman and Rowan, 2007). Similarly, the health condition of street dogs were found to be increased after the ABC program in Kathmandu. Survey results indicated that more street dogs in Kathmandu had healthy skin and improved body condition during 2012 compared with a survey done in 2010 (Kakati, 2012). During our survey we found 57.25\% of females were spayed. The constant number of dogs in Pokhara Valley, despite the efforts of animal birth control, demands for proper study to understand the reason behind this. Though street dogs are spayed, the constant flow of abandoned pet dogs might be one major contributing factor for the constant dog population in Pokhara Valley. 
Street dogs are major source of zoonotic diseases. Approximately 200 people die each year due to rabies in Nepal and about $95 \%$ of human rabies cases were believed to have occurred due to contact with rabid dogs (Dr. Joshi, director NZFHRC, Personal communication). In Nepal, 5.7\% of the dogs in Kathmandu are infected with echinococcosis (Joshi et al., 2007). Street dogs are also the major source of Toxocariasis (Reece, 2005). Dogs excrete these parasites via feces and enter the human body directly or through intermediate hosts. Besides zoonosis, street dogs are creating problems in major cities as they produce noise pollution, disturb drivers and pedestrians, and spread garbage. In our study we found more dogs in the locations where there were slaughter houses. Most of the slaughter houses in Pokhara valley are not well managed. Such slaughter houses can form a hub of dogs for mating as well as for transmitting disease. Interestingly, unmanaged slaughter houses was the main reason put forward by the people in interview.

This survey was carried out in order to design a proper plan for a future ABC program. The opinion put forward by the local residents can give some insight in this. Most of the reasons we observed are related to abandonment of pet dogs making them street dogs. Pet dogs are abandoned for simple reasons such as; when people have too many dogs in their house, when dogs show aggressive behavior, when dogs become sick and when they bite humans and animals. This shows negligence existing in human towards their pets and lack of awareness. Making pet owners aware of pet behavior, veterinary services and birth control possibilities appears necessary and these services should be made feasible to them.

This study showed that the street dog population is persistent in Pokhara Valley. There are a number of unspayed female dogs which can produce large number of pups in a short period of time. Street dogs appear to aggregate near slaughter house and garbage piles which forms a hub for breeding and transmitting diseases. The birth control programs are established attempts to regulate reproduction, but the main reason behind the persistent dog population appears to be abandonment of pet dogs. Dog owners abandon their dogs for simple reasons such as sickness, estrus behavior, sudden aggressive behavior, having too many babies, biting humans/livestock and when they fail to guard human property. All these abnormalities or unwanted dog behaviors can be controlled with veterinary services and proper care. Together with animal birth control programs, generating awareness to pet owners regarding pet behavior, pet keeping and pet health management is also necessary. Veterinary services should also be made easily available and feasible to all.

\section{ACKNOWLEDGEMENT}

First we would like to thank Juliette Cunliffe, founder of Himalayan Animal Rescue Team (HART) for making this study possible. We also like to thank Dibya Baral, Rom Prakash Baral, Himlal Subedi, Tara Subedi, Punye Prasad Paudel, Rabi Baral and Raju Subedi for their help in the survey. Appreciation is extended to Dr. Hem Awasthi and Dr. Sushil Paudel for motivational support.

\section{FUNDING SOURCE}

This is a regular work carried out by Himalayan Animal Rescue Team (HART). HART is a charity organization working for the street dog welfare in Nepal. All the cost during the survey was sponsored by HART. Writing and submitting manuscripts and publication fee will be fully defrayed by the author.

\section{CONTRIBUTION OF EACH AUTHORS}

All the data was collected by Mohan Acharya during office year (2010-2012) at Himalayan Animal Rescue Team (HART, Team; 2010-2012). Santosh Dhakal made the initiation to publish available data in paper format. Both the authors contributed equally during statistical analysis, interpretation, critical revision and preparation of manuscript.

\section{CONFLICT OF INTEREST}

All the survey work done here are supported by HART (www.himalayananimalrescueteam.com). HART is a registered charity organization (2160, Kaski) working for animal welfare in Pokhara Valley, Nepal. This is the first of such survey and there are not any published papers or data available regarding dog population in Pokhara Valley, Nepal. I will take full responsibility regarding the accuracy of survey and data analysis. 


\section{Acharya and S. Dhakal}

\section{REFERENCE}

1. American Pet Products Manufacturer Association (2015). Health benefits of pet ownership fact sheet. Available: www.APPMA.org (accessed 23 March).

2. Baronet D, Waltner-Toews D, Craig PS and Joshi DD (1994). Echinococcus granulosus infection in the dogs of Kathmandu, Nepal. Annals of tropical medicine and parasitology 88: 485-492.

3. Bindari YR, Shrestha S and Shrestha MN (2012). Prevalence of mange infestation in canines of Kathmandu Valley. International Journal of Veterinary Science 1: 21-25.

4. Butler JRA and Bingham J (2000). Demography and dog human relationships of the dog population in Zimbabwean communal lands. Veterinary Record 147: 442-446.

5. Dotson MJ and Hyatt EM (2008). Understanding dog-human companionship. Journal of Business Research 61: 457-466.

6. Geffray L (1999). Infections associated with pets. La Revue de Medecine Interne 20: 888-901.

7. Ghimire P (2003). An unusual site of hydatid cyst: scrotum. Journal of Nepal Medicine Association 40: 217-218.

8. Headey B and Krause P (1992). Health benefits and potential budget saving due to pets: Australian and German survey. Australian Social Monitor 2: 37-41.

9. Hiby LR, Reece JF, Wright R, Jaisinghani R, Singh R and Hiby EF (2011). A mark-resight survey method to estimate the roaming dog population in three cities in Rajasthan, India. BMC Veterinary Research 7: 1-10.

10. Jackman J and Rowan AN (2007). Free-roaming dogs in developing countries: The benefits of capture, neuter, and return programs. In Salem DJ and Rowan AN (Eds). The state of the animals 2007. Human Society Press: Washington, DC, pp 55-78.

11. Joshi DD, Joshi AB and Joshi H (1997). Epidemiology of echinococcosis in Nepal. Southeast Asian Journal of Topical Medicine and Public Health 28: 26-31.

12. Kakati K (2010). Street dog population survey, Kathmandu 2010. Final report to WSPA.

13. Kakati K (2012). Street dog population survey, Kathmandu 2012. Final report to WSPA

14. Kaufman G (2004). Dog sterilization and vaccination program at IAAS, Nepal. Available www.reeis.usda.gov (accessed 23 March 2015).

15. Overgraauw PAM and Knapen F van (2000). Dogs and nematode zoonoses. In CNL Macpherson, FX Meslin and AI Wandeler (Eds). Dogs, zoonosis, and public health. Oxford: CABI, pp. 213-256.

16. Plaut M, Zimmerman EM, and Goldstein RA (1996). Health hazards to humans associated with domestic pets. Annual Review of Public Health 17: 221-245.

17. Rajagopal KV and Rakesh B (2002). Hydatid cyst of the liver presenting as an inferior vena cava obstruction. Journal of Clinical Ultrasound 30: 114-116.

18. Reece JF (2005). Dogs and dog control in developing countries. In Salem DJ and Rowan AN (Eds). The state of the animals 2005. Human Society Press: Washington, DC, pp. 55-64.

19. Rupprecht C, Hanlon C and Hemachudha T (2002). Rabies reexamined. Lancet Infectious Diseases 2: $327-343$.

20. Satyal RC, Manandhar S, Dhakal S, Mahato BR, Chaulagain S, Ghimire L and Pandeya YR (2013). Prevalence of gastrointestinal zoonotic helminths in dogs of Kathmandu, Nepal. International Journal of Infection and Microbiology 2: 91-94.

21. Slater MR (2001). The role of veterinary epidemiology in the study of free-roaming dogs and cats. Preventive Veterinary Medicine 48: 273-286.

22. Slone DE (1988). Ovariectomy, ovariohysterectomy and cesarean section in mares. Veterinary Clinics of North America: Equine Practice 4: 451-459.

23. Tindall B (1975). Pet animals and law. In Proceedings of pet and society. London. pp 120-128.

24. Totton SC, Wandeler AI, Zinsstag J, Bauch CT, Ribble CS, Rosatte RC and McEwen SA (2010). Stray dog population demographics in Jodhpur, India following a population control/rabies vaccination program. Preventive Veterinary Medicine 97: 51-57

25. WHO/WSPA guidelines for dog population management (1990). WHO/ZOON/90/166. 